\title{
O conceito de escritura em Derrida e a gramatologia da sua época
}

\author{
The concept of writing in Derrida and \\ grammatology of his epoch
}

*Moysés Pinto Neto

\begin{abstract}
Resumo: O texto busca explorar a relação entre Da Gramatologia, de Jacques Derrida, e a ciência da sua época. Ele parte de três importantes obras lidas e citadas por Derrida como fontes da sua pesquisa em torno à escritura, Madeleine V-David, André Leroi-Gourhan e a compilação de um Colloque, para explicar o papel da escritura em si mesma no pensamento de Derrida enquanto um sinal do seu materialismo. Para tanto, em contraste com o uso ordinário do termo "escritura", busca compreendê-la metonimicamente como inscrição sulcada no real, buscando a partir do debate interdisciplinar de Derrida entender as múltiplas dimensões pelas quais o problema foi pensado.
\end{abstract}

Palavras-chave: escritura; gramatologia; Derrida; ciência; interdisciplinaridade.

\begin{abstract}
The aim of this paper is to explore the relation between Jacques Derrida's Of Grammatology and the science of its time. We begin with a discussion of three important authors cited by Derrida as sources of his research on writing (écriture): Madeleine V-David, André Leroi-Gourhan and those published in the compilation Colloque. Their work is used to explain the role of writing itself in Derrida's thinking as a sign of his materialism. In contrast to ordinary uses of the term "writing", our task is to understand the latter metonymically as an inscription carved into the real. In virtue of the interdisciplinary debate on Derrida's work, we thus seek to understand the multiple dimensions through which this problem has been thought.

Keywords: writing; grammatology; Derrida; science; interdisciplinarity.
\end{abstract}

\footnotetext{
* Doutor em Filosofia (PUCRS) e Professor da ULBRA. <moysespintoneto@gmail.com>
} 


\section{0 modo não-problematizado da recepção da ideia de escritura}

"... esta conjunção não-fortuita da cibernética e das 'ciências humanas' da escritura conduz a uma subversão mais profunda."

(DERRIDA, Gramatologia)

To momento em que a trilogia inicial da obra de Jacques Derrida Da Gramatologia, A escritura e a diferença e A voz e o fenômeno - completa 50 anos, é interessante retomar o contexto altamente interdisciplinar, criativo e politicamente efervescente em que foi gestada. Não há dúvida que a ideia de escritura (écriture) ${ }^{1}$ está entre os principais tópicos que rememoram o pensamento de Derrida em qualquer círculo intelectual hoje em dia e, naquele momento, foi o elemento que mais caracterizou o seu pensamento, somente alguns anos mais tarde sendo associado à desconstrução. Contrasta com isso, no entanto, a forma como vem sendo conceitualmente desenvolvido pelo próprio campo derridiano, que, apesar das numerosas menções, poucas vezes se debruça sobre a particularidade que o termo recebe no pensamento do filósofo francoargelino. Em geral, o conceito de escritura simplesmente confunde-se com o de escrita, remetendo à ideia de confecção de um texto escrito, sem que as obras em que aparece como motriz sejam cotejadas com as diversas fontes de problematização da qual partem e que discutem na construção do seu aparato conceitual ${ }^{2}$. Vejamos alguns exemplos.

Filósofos de viés mais analítico como Christopher Norris e Leonard Lawlor, por exemplo, não costumam fazer qualquer menção à questão da escritura, mesmo que o último tenha se debruçado sobre a relação com Husserl. Já no confuso livro de Julian Wolfreys toda problemática da escritura remete ao signo, relacionando-o com a origem do significado enquanto efeito da diferença (différance) e articulando a existência de um sentido com a dependência dessa "não-origem" que toma lugar enquanto marcação, vestígio. Espécie de transcendental invisível, essa estrutura "torna-se" e esse "tornar-se não pode ser representado

\footnotetext{
${ }^{1}$ Carla Rodrigues e outros costumam criticar a tradução de "écriture" por "escritura", entendendo que traduzindo simplesmente por escrita se poderia obter um resultado melhor sobretudo por afastar o sentido sagrado oriundo da pesquisa em torno ao judaísmo (RODRIGUES, Carla. "Kafka, Benjamin e Derrida: diante da lei". Terceira Margem, v. 28, p. 86-88, jul./dez. 2013). A razão da manutenção da "escritura" nesse texto é, usando a forma diferente da habitual, dar destaque para outras dimensões que não se confundam com a escrita em particular, embora tampouco essa seja a posição da filósofa no ensaio mencionado.

2 STADEN, Henri. "Writing: empirical, transcendental, ultratranscendental". CR: The New Centennial Review, v. 9, n. 1, Spring 2009, p. 70.
} 
diretamente e, contudo, ..., toma lugar" ${ }^{\prime \prime}$. Esse é o tipo de descrição do pensamento derridiano que, na sua intenção performativa, acaba ficando restrita ao âmbito da mímese e pouco acrescenta em torno da respectiva compreensão, requisito para uma operacionalidade maior dos conceitos na sua dimensão produtiva, criativa, afirmativa. Além disso, deposita em excesso na linguagem a problemática, mesmo que para mostrar seu potencial de jogo e ambivalência, sem apresentar por que, afinal, a escritura desempenha um papel excepcional que, como o próprio Derrida anuncia, deve exceder a dimensão da metáfora, uma das três formas mestras do fechamento logocêntrico (ao lado da teologia e da metafísica). No excelente livro de Martin Hägglund, Radical Atheism: Derrida and the time of life, que sacudiu o cenário norte-americano e europeu nas suas teses polêmicas e gerou uma série de debates em algumas importantes revistas, a ideia de escritura - ao contrário - aparece apenas a partir do rastro, mas dissociando-se quase completamente da dimensão empírica ${ }^{4}$. A perplexidade pela ausência pode ser expressa por um texto-resposta de um dos melhores intérpretes naquele cenário, Henry Staten, nomeado precisamente apenas com a palavra Writing, no qual a distinção entre empírico, transcendental e ultratranscendental se torna mais complicada que a meritória tentativa de Hägglund de separá-las ${ }^{5}$.

Em contexto brasileiro, embora bem mais interessante que Wolfreys e de fundamental importância na recepção do pensamento derridiano, o texto de Duque-Estrada no qual delineia precisamente a ideia de escritura segue uma lógica parecida: ao desconstruir o conceito de signo, coloca a ideia de rastro como um efeito de um sistema de diferenças sem arkhe, operando como jogo liberado do significado transcendental, mas não explica o porquê de o conceito de escritura ser especificamente importante 6 . Da mesma forma, Haddock-Lobo acompanha DuqueEstrada afirmando que "Derrida não pretende pensar a escritura 'fora' da definição tradicional de um 'significante de um significante', mas pensar a positividade dessa 'posição' na cadeia de significação e, mais ainda, da inevitabilidade deste lugar de sempre estar diferido a algo"7. Apesar da importância desses pensadores brasileiros na recepção de Derrida, a retomada do contexto científico-filosófico dos anos 60 ajudará a elucidar que, conquanto essas observações sejam verdadeiras, ainda não são suficientes para explicar o papel da escritura.

3 WOLFREYS, Julian. Compreender Derrida. Rio de Janeiro: Vozes, 2007, p. 106-107.

4 HÄGGLUND, Martin. Radical Atheism: Derrida and the time of life. Stanford: Stanford University Press, 2008, p. 50-75.

5 STADEN, Henri. "Writing: empirical, transcendental, ultratranscendental", p. 77-78.

6 DUQUE-ESTRADA, Paulo César. "Derrida e a escritura". In: Às margens: a propósito de Derrida. Rio de Janeiro: PUC-Rio/Loyola, 2002, p. 27-28.

7 LOBO, Rafael H. Derrida e o Labirinto de Inscrições. Porto Alegre: Zouk, 2008, p. 63 e p. 24-27. 
Há algumas exceções, no entanto, como o trabalho de Christopher Johnson, System and Writting in the Philosophy of Jacques Derrida, livro que traz uma série de temas inusuais para um cenário em que prepondera um tipo de apropriação metafórica do pensamento do filósofo. Johnson relaciona Derrida com a cibernética, o estruturalismo e as ciências da vida e por isso perturba a imagem distorcida de que Derrida seria um filósofo especialmente voltado para a questão da linguagem ${ }^{8}$. Também as filósofas Catherine Malabou ${ }^{9}$ e Vicky Kirby ${ }^{10}$ têm desenvolvido pesquisas interessantíssimas em torno ao impacto da biologia molecular dos anos 60 sobre o conceito derridiano de escritura e as reflexões sobre a técnica de Bernard Stiegler são confessadamente dependentes da visão derridiana acerca da escritura, que Stiegler aproxima da gramatização.

Nesse texto, no entanto, abordarei apenas essas três fontes científicas que fortaleceram a escritura como metonímia de uma série de questões na obra de Derrida, deixando para outros ensaios outras dimensões importantes que precisam igualmente de análise ${ }^{11}$. $O$ objetivo não é policiar apropriações desse pensamento nem necessariamente me opor a esta ou aquela recepção, mas mostrar como a ideia de escritura tem um caráter produtivo se entendida na grade conceitual que Derrida vai construindo nas suas obras iniciais.

\section{A nota de rodapé fundamental em da gramatologia}

Uma das características das primeiras obras de Derrida é a existência discreta de discussões típicas da filosofia francesa dos anos 60 em notas de rodapé e elipses textuais. Ao longo da sua vida, diversas vezes o próprio Derrida menciona que se fazia necessária uma reconstrução de

8 JOHNSON, Christopher. System and writing in the philosophy of Jacques Derrida. Cambridge: Cambridge University Press, 1993, p. 4-6.

9 MALABOU, Catherine. La plasticité au soir de l'écriture: dialetique, destruction, déconstruction. Paris: Éditions Léo Scheer, 2005.

${ }^{10}$ KIRBY, Vicky. "Tracing life: 'la vie la mort'”. The new continental review, v. 9, n. 1, p. 107-126 e "Original science: nature deconstructing itself". Derrida Today (2010).

${ }^{11}$ Como dito, nesse texto me dedicarei exclusivamente à recepção da gramatologia (ciência empírica da escritura) a partir dessas três fontes, tidas como fundamentais pelo próprio Derrida. Esse trabalho deverá ser complementado por outro estudo que discuta a matriz biocibernética que Derrida recebe, em especial no diálogo com Jean Hyppolite e o debate sobre a mathesis universalis, e um terceiro que discuta a relação dessa pesquisa em torno a mathesis com a "fenomenologia matemática", corrente de estudos capitaneada por Louis Althusser (e com os fundamentais trabalhos de Suzanne Bachelard e Tran Duc Thao) que influenciou os primeiros ensaios de Derrida acerca de Husserl, inserindo-o no cenário do materialismo francês. A referência no diálogo entre Derrida e a biocibernética é Johnson. Já para o diálogo com a "fenomenologia matemática", ver Baring. Para um esboço sintetizado de todas essas relações, ver PINTO NETO, Moysés. A escritura da natureza: Derrida e o materialismo experimental. Tese de Doutorado defendida no PPG Filosofia da PUCRS. Porto Alegre, 2013, p. 85-88 e 132-151. 
todo cenário da Rue D'Ulm (local onde está a ENS) a partir do qual se chegaria a muitas descobertas surpreendentes. A biografia de Benoît Peeters e o trabalho arquivístico de Edward Baring são, hoje, sinais de que esse trabalho pode iluminar muitos aspectos do próprio pensamento derridiano, familiarizando o leitor com diversos fios desse tecido que se encontram desconectados por aqueles que se aproximaram da desconstrução sem levar em consideração seu cenário de surgimento. Essa situação é paradoxal, na medida em que o próprio Derrida diversas vezes situava sua intervenção como estratégica, isto é, situada em contexto determinado, e a desconstrução não cansa de afirmar o quanto a contingências das relações de poder e da historicidade dos corpos em geral é capaz de produzir determinadas relações intelectuais. A desconfiança em relação aos binarismos e às falsas simetrias, por exemplo, é um exemplo típico da situação de cada intervenção, e o próprio pensamento de Jacques Derrida não poderia escapar a essa regra.

Na Advertência que abre Da Gramatologia Derrida afirma que "a primeira parte deste ensaio, 'A escritura antes da letra', desenha em traços largos uma matriz teórica"12. Em outros termos, trata-se da matriz teórica que servirá de apoio para as obras subsequentes, da enunciação positiva de um programa (como o próprio Derrida nomeará ${ }^{13}$ ), que irá balizar seus esforços. Ao mesmo tempo, o filósofo, logo ao lado do nome da seção, diz o seguinte em nota de rodapé:

Pode-se considerá-la [a matriz teórica desenhada em traços largos, MPN] como o desenvolvimento de um ensaio publicado na revista Critique (dezembro de 1965-janeiro de 1966). A ocasião nos fora proporcionada por três importantes publicações: M. V-David. Le débat sur les écritures et l'hiéroglyphe aux XVII' e XVIII siècles (1965) (DE); A. Leroi-Gourhan, Le geste et la parole (1965) (GP); L'écriture et la psychologie des peuples (Actes d'un colloque, 1963) (EP) ${ }^{14}$.

Em outros termos, Derrida enuncia sua matriz teórica e logo em sequência atribui a ocasião ao lançamento desses três livros. A biografia de Peeters mostra que $A$ escritura antes da letra foi texto que causou arrebatamento em filósofos da estirpe de Michel Foucault (que o considera "o texto mais radical" que já lera), Jean Hyppolite (que deseja o publicar

\footnotetext{
${ }^{12}$ DERRIDA, Jacques. Gramatologia. Trad. Miriam Chnaiderman e Renato Janine Ribeiro. São Paulo: Perspectiva, 2004, p. VII, tradução modificada. Utilizarei as traduções brasileiras dos textos de Derrida com ligeiras modificações na tradução (sempre expressamente anunciadas) e consultando a versão original, embora não explicitamente a mencionando.

${ }^{13}$ DERRIDA, Jacques. Gramatologia, p. 8.

${ }^{14}$ DERRIDA, Jacques. Gramatologia, p. VII.
} 
como novo volume da coleção Epimethée), Michel Deguy, Emmanuel Levinas (para quem o texto é "incandescente") e François Châtelet (passando a considerá-lo "dos grandes pensadores do século"). Peeters começa destacando justamente a menção a esses três textos - que arrola a seguir - dos quais A escritura antes da letra seria à primeira vista "uma resenha", mas "as questões vão muito além"15. Trata-se, portanto, de escrito que ocupa posição singular na obra do filósofo franco-argelino. Apesar disso, muito raramente essas relações são trabalhadas entre os intérpretes. No volume sobre De la Grammatologie recentemente editado pela editora Continuum em 2011, organizado por Sean Gaston e Ian Maclachlan, praticamente nada é dito sobre as três obras, salvo a menção de Christopher Johnson, cujos trabalhos com o "imaginário cibernético" já haviam abordado a temática, embora quase sempre com foco exclusivo nas relações com André Leroi-Gourhan ${ }^{16}$. Os trabalhos de Bernard Stiegler, em especial os três volumes de La technique et le temps, também têm uma preocupação na recuperação da importância de Leroi-Gourhan.

O que os três livros têm em comum é exatamente o fato de cuidarem do conceito de escritura: no caso de Madeleine V-David, narrando a história da decifração dos hieróglifos e todos os "obstáculos epistemológicos" que lhe bloquearam ao longo dos últimos séculos; em Leroi-Gourhan a partir da antropogênese e sua relação com a técnica na leitura paleontológica que ele trava da natureza; por fim, os atos de um colóquio em torno da ciência da escritura, reunindo pesquisadores de diversas áreas e tendências a fim de consolidar o saber acumulado em torno do tema. Em um clima marcado pela presença do estruturalismo, no qual a abordagem interdisciplinar que Claude Lévi-Strauss havia inaugurado predominava, esses três trabalhos parecem ter desempenhado um papel especial na construção do papel da escritura para Derrida. Todos os grandes filósofos dessa época - p.ex., Lyotard, Foucault, Deleuze, Serres - tinham como característica esse diálogo interdisciplinar com as ciências da época, não escapando Derrida à regra. A intuição da escritura - embora de matriz husserliana nos seus estudos (com todas as possíveis variações genealógicas) - parece ter encontrado também sua base

${ }^{15}$ PEETERS, Benoît. Derrida. Trad. André Telles. Rio de Janeiro: Civilização Brasileira, 2013, p. 203-209. Expressamente: "Derrida reconheceu isso em diversas oportunidades: aquele artigo, esboço da primeira parte da Gramatologia, é a 'matriz' que condicionará o conjunto do seu trabalho futuro. Obedecendo à regra que prevalece em Critique, o texto se apresenta à primeira vista como resenha de três livros: (...) Mas as questões abordadas em 'A escritura antes da letra' vão muito além" (idem, p. 204).

${ }^{16}$ JOHNSON, Christopher. 2001. Derrida: a cena da escritura. São Paulo: Editora UNESP, 2001, p. 43-45; idem, "The cybernetic imaginary". In: Reading Derrida's Of Grammatology. Ed. Sean Gaston e Ian Maclachlan. London: Continuum, 2011, p. 11-14. 
científica, numa equivalência simétrica à fonologia em relação ao estruturalismo ${ }^{17}$.

\section{Madeleine V-David e a ciência da decifração}

Madeleine V-David explora em seu livro o desenrolar histórico do processo de deciframento dos hieróglifos egípcios e os ideogramas chineses, mostrando como três grandes preconceitos obstaculizavam seu real desenvolvimento: o "preconceito hieroglifista" enquanto exaltação do caráter "misterioso" ou "simbólico" dos hieróglifos, presente sobretudo nos trabalhos do Padre Kircher e no romantismo; o "preconceito antifigurativo", que rechaçava qualquer tipo de valor para a forma dos caractere ${ }^{18}$, redundando no "preconceito mexicano" (comparação entre os hieróglifos egípcios e pinturas figurativas encontradas no México) e, inversamente, no "preconceito chinês" (submissão da compreensão da escritura chinesa a uma ideia de escritura universal, com vistas a criar uma "língua filosófica" capaz de ultrapassar as particularidades locais") ${ }^{19}$; finalmente, o "preconceito teológico", consistente na ideia de que o alfabeto semítico teria origem divina ${ }^{20}$. Madeleine V-David demonstra como a ciência da escritura e a decifração somente puderam realmente nascer, a partir dos trabalhos de Fréret, Warburton, Barthélemy, Dacier, culminando em Champollion, quando foram ultrapassados todos esses preconceitos, devolvendo à escritura sua historicidade e complexidade. Assim, em primeiro lugar o que Derrida recolhe desse trabalho é a rede de repressões que impede a plena historicidade da escritura aflorar, submetendo-a a uma série de "obstáculos epistemológicos" que cegam quanto ao seu desenvolvimento. Essa noção bachelardiana aparece em Madeleine V-David como "preconceito", repetindo-se nesses termos em $A$ escritura antes da letra para depois receber ${ }^{21}$, a partir de uma historicização de verniz hegeliano cujo sentido não podemos explicar aqui, uma "Necessidade" - no sentido de que todas as condições que retroativamente podemos visualizar hoje foram necessárias para que a visão de tornasse possível ${ }^{22}$.

${ }^{17}$ DERRIDA, Jacques. Gramatologia, p. 35; JOHNSON, Christopher. System and Writing, p. 6-9.

${ }^{18}$ DAVID, Madeleine V. Le débat sur les écritures at l'hiéroglyphe aux XVIIe et XVIIIe siècles - et la application de la notion de déchiffrement aux écritures mortes. Paris: S.E.V.E.N, 1965, p. 13.

${ }^{19}$ DAVID, Madeleine V. Le débat sur les écritures at l'hiéroglyphe aux XVIIe et XVIIIe siècles et la application de la notion de déchiffrement aux écritures mortes, p. 14-15.

${ }^{20}$ DAVID, Madeleine V. Le débat sur les écritures at l'hiéroglyphe aux XVIIe et XVIIIe siècles et la application de la notion de déchiffrement aux écritures mortes, p. 102-103; DERRIDA, Jacques. Gramatologia, p. 93.

${ }^{21}$ DERRIDA, Jacques. Gramatologia, p. 100.

22 DERRIDA, Jacques. Gramatologia, p. 94. 
No primeiro momento, a gramatologia (ciência da escritura), baseada na erudição do Padre Kircher, toma os hieróglifos egípcios como alegorias, alternando entre a busca da chave para compreensão de um significado oculto $^{23}$ até o papel do símbolo como simples marca aristocrática edificante ${ }^{24}$. A partir de então, a associação com os números começa a preponderar, deslizando o enfoque para a coexistência entre símbolos e números e comparação entre o hieróglifos egípcios e pinturas antigas encontradas no México ${ }^{25}$. Com isso, o modelo místico começa a perder força em relação a um modelo criptográfico no qual a linguagem fonética perderá espaço em relação a notações mais precisas, próximas da matemática, capazes de expressar uma "língua filosófica" 26. Mais tarde, no ensaio Freud e a cena da escritura, Derrida retomará o debate sobre a criptografia a partir da questão da decifração do sonho na psicanálise freudiana ${ }^{27}$.

O século XVIII teria sido o momento em que a abertura historicista teria sido possível, embora tenha sido parcialmente bloqueado de novo pelo século seguinte, afirma Madeleine V-David ${ }^{28}$. A autora, mencionada em diversas notas, para Derrida era "um dos espíritos que, na França, animaram incessantemente o levantamento histórica da escritura pela vigilância da questão filosófica"29. Ela teria auxiliado a demonstrar o teologismo que é mais que um preconceito e "sob todas as suas formas, quer sejam manifestas ou sorrateiras", "constituiu o obstáculo maior a toda gramatologia", já que "nenhuma história da escritura podia conciliarse com ele" ${ }^{30}$. Será sobretudo quando comenta Leibniz e Descartes, onde a ideia de escritura universal (poligrafia) bloqueava a compreensão dos ideogramas chineses ${ }^{31}$, que Derrida irá dialogar diretamente com David, à medida que, contra a tradição fonocêntrica presente desde o Fedro, Leibniz busca uma escritura que não se submeta à linguagem fonética com suas "imperfeições". Contra o analiticismo intuicionista

${ }^{23}$ DAVID, Madeleine V. Le débat sur les écritures at l'hiéroglyphe aux XVIIe et XVIIIe siècles et la application de la notion de déchiffrement aux écritures mortes, p. 27-28.

${ }^{24}$ DAVID, Madeleine V. Le débat sur les écritures at l'hiéroglyphe aux XVIIe et XVIIIe siècles et la application de la notion de déchiffrement aux écritures mortes, p. 24, 43-46.

${ }^{25}$ DAVID, Madeleine V. Le débat sur les écritures at l'hiéroglyphe aux XVIIe et XVIIIe siècles et la application de la notion de déchiffrement aux écritures mortes, p. 30.

${ }^{26}$ DAVID, Madeleine V. Le débat sur les écritures at l'hiéroglyphe aux XVIIe et XVIIIe siècles - et la application de la notion de déchiffrement aux écritures mortes, p. 31.

${ }^{27}$ DERRIDA, Jacques. A Escritura e a Diferença. Trad. Maria B. M. Nizza da Silva et al. 4. ed. São Paulo: Perspectiva, 2010, p. 305-310.

${ }^{28}$ DAVID, Madeleine V. Le débat sur les écritures at l'hiéroglyphe aux XVIIe et XVIIIe siècles et la application de la notion de déchiffrement aux écritures mortes, p. 73-74.

${ }^{29}$ DERRIDA, Jacques. Gramatologia, p. 93.

${ }^{30}$ DERRIDA, Jacques. Gramatologia, p. 94.

${ }^{31}$ DAVID, Madeleine V. Le débat sur les écritures at l'hiéroglyphe aux XVIIe et XVIIIe siècles et la application de la notion de déchiffrement aux écritures mortes, p. 62. 
cartesiano, Leibniz proporia um que "remete para além da evidência, para a ordem, a relação, o ponto de vista" ${ }^{32}$. Ao fazer isso, no entanto, não estaria verdadeiramente liberando a escritura do seu valor subordinado, mas submetendo-a à primazia do logos na ideia de transparência que, paradoxalmente, torna opaca a compreensão do ideograma chinês. Ao valorizar a escritura chinesa contra a ocidental, o filósofo da Monadologia estaria reproduzindo uma "alucinação europeia" que funciona como etnocentrismo invertido a partir do qual o Ocidente se autoelogia projetando-se sobre uma cultura cujo real funcionamento, por sua vez, é ocultado ${ }^{33}$. Portanto, no fim das contas o que prevaleceria ainda e sempre seria a remissão a "uma teoria infinitista e ao logos ou entendimento infinito de Deus" 34 .

Em todo caso, o que o trabalho de Madeleine V-David demonstra é que somente a partir do "corte epistemológico" de Fréret e Warburton, liberando-se dos preconceitos chinês e hieroglífico, "pode então nascer uma reflexão sistemática sobre as relações entre escritura e fala" 35 . Assim, a ciência da escritura até atingir sua maturidade teria oscilado permanentemente entre dois polos: o da transparência total, com a escrita baseada na notação matemática, e a opacidade total, fundada na mística e no ocultismo. Tudo que escapa ao fonetismo desliza entre os preconceitos hieroglífico e chinês, entre o segredo absoluto e a língua universal, Padre Kircher e John Wilkins. Somente a partir de Nicolas Fréret o preconceito chinês será derrubado, quando os estudos sinológicos alcançaram o ponto máximo na gramatologia francesa a partir da maestria de France Arcadius Hoang, também mestre de Montesquieu. Para Fréret, é preciso reinserir Egito e China na história, compreendendo que a escritura ideogramática chinesa não só não constitui qualquer padrão universal, como inclusive contraria as ideias que os filósofos cultivariam enquanto "mito da China" ${ }^{36}$. E com Warburton, algum tempo mais tarde, a gramatologia poderá pensar o devir da escritura, dissociando-o da ampla rede de preconceitos que a reprimiam. Finalmente, Champollion irá perspectivar a história da escritura, concebendo Kircher como apenas um teórico imaginativo e Warburton como um desbravador de caminhos, ainda que permanecendo vinculado a um modelo superado. A partir do seu método, torna-se possível explicar a passagem da escritura

\footnotetext{
32 DERRIDA, Jacques. Gramatologia, p. 97; DAVID, Madeleine V. Le débat sur les écritures at l'hiéroglyphe aux XVIIe et XVIIIe siècles - et la application de la notion de déchiffrement aux écritures mortes, p. 66-67.

${ }^{33}$ DERRIDA, Jacques. Gramatologia, p. 98-99.

${ }^{34}$ DERRIDA, Jacques. Gramatologia, p. 97.

${ }^{35}$ DERRIDA, Jacques. Gramatologia, p. 101.

${ }^{36}$ DAVID, Madeleine V. Le débat sur les écritures at l'hiéroglyphe aux XVIIe et XVIIIe siècles et la application de la notion de déchiffrement aux écritures mortes, p. 95-103.
} 
hieroglífica para a alfabética, uma vez que restitui o sentido histórico aos hieróglifos ${ }^{37}$.

\section{A escritura e a psicologia dos povos: atas de um colóquio}

Na sua leitura do livro L'écriture et la psychologie des peuples, registro de intervenções sobre a história da escritura nas diversas culturas pelo Centre International de Synthèse em colóquio no qual estiveram presentes, para além dos conferencistas, Alexandre Koyré e a própria Madeleine V-David, Derrida privilegia os exemplos e as teses mais arrojadas que lhe permitem confirmar suas teses em torno da primazia da escritura. As atas combinam intervenções mais convencionais, próximas de uma aproximação arqueológica (no sentido tradicional) da escritura, com aquelas que procuram estender o sentido das conclusões empíricas para redesenhar o papel da escritura. Evidentemente, Derrida se sentirá mais à vontade com as escrituras chinesa e egípcia dentre os exemplos empíricos. O sentido político da escritura, ademais, será abordado seguidas vezes, mostrando-se as relações entre as formas de escrita, divisões sociais e estruturas de poder ${ }^{38}$.

Nas Conclusões e Confrontações, em particular, o diálogo avança em um sentido bem próximo daquele que Derrida desenvolve em $\mathrm{Da}$ Gramatologia. Em meio aos debates, a questão em torno da natureza da escritura matemática é levantada e as respostas se encaminham na direção da dependência da matemática em relação à escrita e seu caráter completamente não-fonético. As teses retomam também a introdução à "Origem da Geometria", de Husserl, em torno da escritura como condição da geometria (isto é, da possibilidade de idealização) e lançam para adiante da gramatologia, fazendo a interface com a cibernética e a diluição do binômio natural/artificial (natureza/cultura) que ela buscará trabalhar ${ }^{39}$.

\footnotetext{
${ }^{37}$ DERRIDA, Jacques. Gramatologia, p. 100-101; DAVID, Madeleine V. Le débat sur les écritures at l'hiéroglyphe aux XVIIe et XVIIIe siècles - et la application de la notion de déchiffrement aux écritures mortes, p. 128-133.

${ }^{38}$ Por exemplo, DERRIDA, Jacques. Gramatologia, p. 115-117.

${ }^{39}$ Vale a pena ler a transcrição do trecho que vem em forma de diálogo nos anais:

"Février: "A moins d'avoir une mémoire extraordinaire de cheval calculateur, un mathématicien ne pourrait pas poser une équation et la résoudre sans l'aide de l'écriture. C'est une langue spéciale qui n'a plus aucun rapport avec la langage, c'est une espèce de langue universelle, c'est-à-dire que nous constatons par les mathématiques que le langage - je me venge des linguistes - est absolument incapable de rendre certaines formes de la pensée moderne. Et à ce moment-là l'écriture, qui a été tellement méconnue, prend la place du langage, après avoir été sa servant, parce que le langage est incapable de suffire aux mathématiciens: on ne les conçoit pas travaillant sans tableau noir. C'est uniquement l'écriture dans ce cas-là qui remplace le langage. Or les mathématiques envahissent de plus en plus notre vie; autrefois,
} 
Février, que é citado diversas vezes em $D a$ Gramatologia ${ }^{40}$ chega a ponto de afirmar que se trataria de uma "vingança da escritura sobre a linguagem" de uma maneira totalmente similar ao modo como Derrida trabalha sua crítica ao fonocentrismo estruturalista. Além disso, a própria diversidade de escrituras que o colóquio apresenta demonstra que qualquer tentativa de estabelecer a primazia do modelo fonológico, em especial remetendo ao "espírito humano" ou qualquer outro tipo de conceito metafísico, contrasta com as próprias soluções diferentes encontradas pelas diversas culturas para a escritura. Para dar um exemplo anedótico, em determinado momento, após a apresentação da escritura chinesa, ocorre o debate em torno do porquê de os povos do Extremo Oriente não adotarem a escritura alfabética: de forma ligeiramente cômica para este leitor, um dos debatedores responde que, no Japão, dada a erradicação completa do "analfabetismo", o "problema" simplesmente não aparece. Não haveria motivo, a não ser o mimetismo puro e simples do Ocidente, para "melhorar" uma cultura sedimentada em longa tradição41. Em outro momento, comentando a escritura indiana, Cohen e outros sublinham como a sabedoria não estaria lá associada ao ato de escrever ${ }^{42}$, percebendo-se este muito mais como um ato burocrático subordinado (o mesmo se dá em certo período de Roma) $)^{43}$. São exatamente esses focos de restrição de Derrida em torno do trabalho, aparecendo mais de uma vez em Da Gramatologia como uma teleologia francamente etnocêntrica ${ }^{44}$.

il y avait la géométrie qui est une forme concrète des mathématiques, mais depuis ce temps-là il y a eu l'algèbre, toutes les formes supérieures des mathématiques, on va même beaucoup plus loin: nous avons des sciences qui paraîtraient ne pas être sciences et relever uniquement lu libre arbitre, comme la démographie ou bien encore comme le calcul des probabilités; les mathématiciens disent que c'est leur domaine que le calcul des probabilités, et ils nous le prouvent. Par conséquent, nous nous trouvons en présence d'une science que repose uniquement sur l'écriture et qui récuse le langage, et cette science-là envahit de plus en plus tous les domaines de notre vie : je trouve que c'est une revanche magnifique de l'écriture sur le langage.

Bouligand. - Il y a autre revanche: c'est celle des machines, qui procèdent actuellement par un système de numération binaire, et on pourrait dire que c'est la numération binaire qui est devenue en quelque sorte de grand maître de la situation. Mais sans toutefois sortir d'un rôle schématique, rôle qui est vite débordé quand on songe à retrouver des interprétations concrètes.

Février. - J'ai vu récemment un jeune biologiste, le Dr. Cara, à qui je faisais justement remarquer cela: qu'il y avait certaines formes de la mentalité primitive, comme des formes d'oracles, qui reposent sur le système binaire. (...) en physiologie, tout le système nerveux fonctionne par réactions binaires. De ce point de vue-là nous retombons dans le système mathématique : encore une preuve que les mathématiques envahissent tout" (CENTRE INTERNATIONAL DE SYNTHËSE. L'écriture et la psychologie des peuples. XXII Semaine de Synthèse. Paris: Armand Colin, 1963, p. 349).

${ }^{40}$ Por exemplo, DERRIDA, Jacques. Gramatologia, p. 9.

${ }^{41}$ CENTRE INTERNATIONAL DE SYNTHÈSE. L'écriture et la psychologie des peuples, p. 43.

${ }^{42}$ CENTRE INTERNATIONAL DE SYNTHÈSE. L'écriture et la psychologie des peuples, p. 154-156.

${ }^{43}$ CENTRE INTERNATIONAL DE SYNTHĖSE. L'écriture et la psychologie des peuples, p. 207.

${ }^{44}$ Por exemplo, DERRIDA, Jacques. Gramatologia, p. 114-115. 
O fonologocentrismo, lembre-se, é também uma forma de etnocentrismo. Mesmo a oposição entre pictogramas e escritura fonética será posta em questão, já se considerando o fenômeno do pictograma como resultado da arquiescritura ${ }^{45}$, algo que está de acordo com as teses mais radicais de Leroi-Gourhan em torno da técnica.

Apesar disso, Derrida considerava que os gramatólogos ainda estabeleciam suas questões a partir da ideia de origem, perguntando-se "onde e quando começa a escritura?", circulando, com isso, "em conceitos realmente pouco criticados" e movendo-se "em evidências que desde sempre parecem óbvias". E segue:

Ao redor destas respostas, de cada vez ordenam-se uma tipologia e uma perspectiva do devir das escrituras. Todas as obras que tratam da história da escritura são compostas da mesma forma: uma classificação de tipo filosófico e teleológico esgota os problemas críticos em algumas páginas, passando-se em seguida à exposição dos fatos. Contraste entre a fragilidade teórica das reconstruções e a riqueza história, arqueológica, etnológica, filológica da informaçã̃o ${ }^{46}$.

Em outros termos, segundo a longa tradição francesa de Bergson, Cavaillès, Bachelard, Althusser e tantos outros, Derrida contrasta as descobertas positivas da ciência gramatológica com a "lógica filosofante" que a permite, por razões que talvez se justifiquem economicamente, recalcar a questão ontofenomenológica da essência que caberia indagar. Em outros termos, as descobertas positivas do mundo científico contrastam com o quadro filosófico tradicional que lhe daria base, num quadro de permanente excesso em relação à tentativa de totalização logocêntrica. Ou, nas suas palavras, "o conceito da ciência ou da cientificidade da ciência (...) sempre foi determinado como lógica - (...) sempre foi um conceito filosófico, ainda que a prática da ciência nunca tenha cessado, de fato, de contestar o imperialismo do logos, por exemplo fazendo apelo, desde sempre e cada vez mais, à escritura não-fonética"47. Assim, o pensamento do grafema (rastro, trace), formulado a partir da gramatologia, curto-circuito a própria relação entre a questão de fato (exemplos empíricos da escritura, própria da ciência) e de direito (origem ou essência, própria da ontologia e da fenomenologia). Na medida em que "o rastro não é nada, não é um ente, excede a questão o que é e eventualmente a possibilita. Aqui", segue Derrida, "não se pode nem mesmo confiar na oposição do fato e do direito, que nunca funcionou a não

\footnotetext{
${ }^{45}$ CENTRE INTERNATIONAL DE SYNTHÈSE. L'écriture et la psychologie des peuples, p. 11.

${ }^{46}$ DERRIDA, Jacques. Gramatologia, p. 35.

${ }^{47}$ DERRIDA, Jacques. Gramatologia, p. 4.
} 
ser no sistema da questão o que é, sob todas as suas formas metafísicas, ontológicas e transcendentais" 48 .

\section{Leroi-Gourhan: reserva, programa, exteriorização}

É precisamente quando Derrida problematiza o conceito "instrumentalista" de escritura (pelo qual a linguagem é um instrumento e a escritura seu prolongamento), ao afirmar que a "teoria da escritura não precisa apenas de uma liberação intracientífica e epistemológica", mas que se deve empreender uma reflexão na qual a "descoberta positiva" e a "desconstrução" (uma das poucas menções à palavra entre os primeiros ensaios) se controlem minuciosa e laboriosamente ${ }^{49}$, que a figura de André Leroi-Gourhan, a terceira das obras mencionadas, aparece ${ }^{50}$. A gramatologia não se enquadra nem nas ciências humanas nem nas regionais, sequer recebendo seu vocabulário da metafísica. A conexão entre sua novidade, de um lado, e a repercussão conceitual que desencadeia, de outro, anunciam uma nova relação entre filosofia e ciência que não cabe no modo fundacionista dominante (filosofia como "ciência-rainha"), por exemplo, ainda no seio da filosofia de Heidegger ${ }^{51}$. Da mesma forma, Derrida - como já fizera também Alfred Métraux no Colóquio $^{52}$ - utiliza o pensamento de Leroi-Gourhan para avançar sua tese em torno à escritura entre os "primitivos", desenvolvida na segunda parte do trabalho, em confronto com Lévi-Strauss ${ }^{53}$.

Nesse caso, como já dito, o aporte não foi subestimado pelos intérpretes derridianos, especialmente Bernard Stiegler e Christopher Johnson. Mencionado pelos gramatólogos no Colóquio recém citado ${ }^{54}$, além de ser referência para filósofos do nível de Gilbert Simondon ${ }^{55}$, Gilles Deleuze e Félix Guattari ${ }^{56}$, Leroi-Gourhan parece ter exercido uma influência significativa por ter transcendido o nível paleontológico para uma espécie de história da técnica como processo condutor da evolução

${ }^{48}$ DERRIDA, Jacques. Gramatologia, p. 92.

${ }^{49}$ DERRIDA, Jacques. Gramatologia, p. 102-103.

${ }^{50}$ Além das influências teóricas, Leroi-Gourhan foi orientador de tese de Marguerite Derrida no curso de etnologia, quando esta pesquisava a liturgia dos sefarditas de Argel (PEETERS, Derrida, p. 151).

${ }^{51}$ DERRIDA, Jacques. Gramatologia, p. 109.

${ }^{52}$ CENTRE INTERNATIONAL DE SYNTHÈSE. L'écriture et la psychologie des peuples, p. 19-20.

${ }^{53}$ DERRIDA, Jacques. Gramatologia, p. 104.

${ }^{54}$ CENTRE INTERNATIONAL DE SYNTHESSE. L'écriture et la psychologie des peuples, p. 24-26.

${ }^{55}$ A relação com Gilbert Simondon foi exaustivamente explorada por Bernard Stiegler (1998, p. 43-81). Pode-se ler no próprio Leroi-Gourhan passagens que, inversamente, remetem ao trabalho de Simondon (LEROI-GOURHAN, O Gesto e a Palavra, v. II - Memória e Ritmos, p. 46 e 105).

${ }^{56}$ DELEUZE, Gilles e GUATTARI, Félix. Mil Platôs, v. 1. Trad. Aurélio Guerra e Costa Pinto. Rio de Janeiro: Editora 34, 1995, p. 77. 
das espécies. Segundo Leroi-Gourhan, "a Pré-História, subentendida por uma metafísica religiosa ou por uma dialética materialista, tem como única significação real situar o homem futuro no seu presente e no seu passado mais longínquo" 57 . A leitura paleontológica permite desfazer preconceitos e explicar a relação profunda entre a vida e a técnica.

Em Da Gramatologia o trabalho O Gesto e a Palavra, em dois volumes, aparece como referência central. Nele, Leroi-Gourhan desenvolve o movimento das espécies que, na deriva evolutiva, desaguaram no humano. Após o declínio do etnocentrismo religioso a partir da emergência do pensamento naturalista, o principal adversário é o "mito cerebralista" de Rousseau, pelo qual "o 'homem natural', equipado com todos os atributos atuais, partindo do zero inicial imitando os animais e raciocinando depois, inventa pouco a pouco tudo o que na ordem técnica e social o conduz ao mundo de hoje" ${ }^{58}$. O mesmo Rousseau que Derrida utilizará, cruzando-o com Claude Lévi-Strauss, como denominador de uma "época" fonologocêntrica. Mais tarde, Stiegler, com as mesmas fontes (LeroiGourhan, Heidegger e Derrida), irá buscar construir uma antropologia filosófica que seja, ao mesmo tempo, filosofia da técnica justamente a partir da crítica a Rousseau e o "mito cerebralista". Para tanto, será necessário mostrar não apenas como as ferramentas como necessárias, no jogo entre "córtex e sílex" (tese de Stiegler), para a antropologização, mas como o humano é resultado de uma escritura que joga sempre arrombando seus respectivos limites, naquilo que se chamou "lógica do suplemento" (tese de Derrida) ${ }^{59}$ (DERRIDA/STIEGLER, 2002, p. 52-53). Após a ciência da escritura, por meio de Madeleine V-David e dos diversos autores do Colóquio, mostrar que a escrita é irredutível ao modelo fonológico, trata-se de demonstrar a prioridade do fenômeno da escritura a partir do seu alargamento metonímico. Há, portanto, uma triangulação entre Rousseau e Lévi-Strauss e Leroi-Gourhan na qual Derrida irá colocar o último como contraponto ao fonologocentrismo, relacionando escritura e técnica para fazer com que ela anteceda a própria linguagem (logos).

Leroi-Gourhan inverte a relação entre cérebro e os pés, fazendo com que a posição vertical fosse determinante para que o cérebro humano pudesse se desenvolver. Para ele, "comprovar com o zinjantropo que a humanização começa pelos pés é talvez menos exaltante do que imaginar o pensamento despedaçando as limitações anatômicas para se forjar um cérebro, mas é um caminho bastante seguro"60.

\footnotetext{
${ }^{57}$ LEROI-GOURHAN. O Gesto e a Palavra, v. I - Técnica e Linguagem. Porto: Edições 70, 1983, p. 12. ${ }^{58}$ LEROI-GOURHAN. O Gesto e a Palavra, v. I - Técnica e Linguagem, p. 18.

${ }^{59}$ DERRIDA, Jacques \& STIEGLER, Bernard, 2002. Echographies of Television. Trad. Jennifer Bajorek. Polity, 2002, p. 52-53.

${ }^{60}$ LEROI-GOURHAN. O Gesto e a Palavra, v. I - Técnica e Linguagem, p. 150.
} 
O processo de liberação da mão a partir da posição vertical teria liberado o manuseio de utensílios que, somado à face curta, constituiriam os verdadeiros critérios diferenciais do humano ${ }^{61}$. Impossível não ler ressonâncias materialistas na inversão do platonismo enquanto primazia da "cabeça" (também da "altura") sobre os "pés" (a base da pirâmide), refletindo a prevalência do ideal sobre o material e do intelectual sobre o terreno como elementos essenciais da tradição filosófica ${ }^{62}$. Leroi-Gourhan demonstra a continuidade que se dá entre as espécies, começando da origem da vida, a fim de romper com qualquer tipo de especialidade humana que remeta a conteúdos religioso-espirituais, subvertendo o antropocentrismo humanista da tradição. Interessante, contudo, que em certo momento o paleontólogo, investigando justamente a passagem ao humano na relação entre utensílios e o cérebro, utiliza a expressão "charneira" (brisure) para definir a posição dos paleantropídeos na evolução ${ }^{63}$, possivelmente sendo uma das fontes da tese intermediária, ao lado da própria carta de Roger Laporte, entre ruptura e continuísmo que Derrida adota na própria Gramatologia.

O conceito de "liberação", induzido geralmente por algum "upgrade" motor - especialmente a partir de modificações no esqueleto - faria com que os seres vivos fossem gradualmente desvinculando órgãos da sua função originária, tornando-se por isso menos presos ao meio em que vivem:

A mão que liberta a palavra, é exatamente aí que a paleontologia chega. Se a paleontologia chega aí por uma via muito diferente da de Gregório de Nisa, como ele, contudo, ela fala de 'libertação', para caracterizar a evolução em direção aos cumes da consciência humana. De facto, numa perspectiva que vai do peixe da era primária ao homem da era quaternária, julgamos assistir a uma série de libertações sucessivas: a do corpo inteiro em relação ao elemento líquido, a da cabeça em relação ao solo, a da mão em relação à locomoção e, finalmente, a do cérebro em relação à máscara facial ${ }^{64}$.

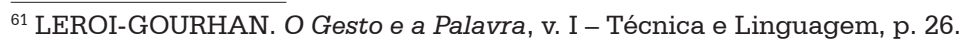

${ }^{62}$ Além das referências materialistas e naturalistas diretamente assumidas (LEROI-GOURHAN. O Gesto e a Palavra, v. I - Técnica e Linguagem, p. 14-17, 150-152), é possível ver a relação de Leroi-Gourhan com o clássico trabalho de Engels sobre a técnica (agradeço ao colega Victor Marques pela lembrança). Por outro lado, como já destacado no capítulo sobre epistemologia francesa, as pontes com Henri Bergson, Teillard de Chardin (idem, p. 61-62), e Gaston Bachelard, com quem compartilhava uma visão muito parecida acerca das relações entre psicanálise e epistemologia (idem, p. 28-29), são explícitas e implícitas. Ver ainda, da mesma obra, p. 108-110.

${ }^{63}$ LEROI-GOURHAN. O Gesto e a Palavra, v. I - Técnica e Linguagem, p. 134.

${ }^{64}$ LEROI-GOURHAN. O Gesto e a Palavra, v. I - Técnica e Linguagem, p. 31. 
Leroi-Gourhan, entretanto, estava atento ao que qualquer biólogo de hoje, e o próprio Darwin, sempre afirmou: a palavra "evolução" não deve carregar a conotação de hierarquia ou teleologia, indicando apenas o processo de deriva natural que potencializa vantagens segundo a adaptação a meios naturais variáveis ${ }^{65}$. A figura do zinjantropo, fóssil descoberto em 1959 acompanhado de utensilagem, provaria que a técnica e a forma corporal antecedem o desenvolvimento mental ${ }^{66}$. O que o interessa, no entanto, é como a mobilidade é característica primordial em relação à inteligência a que normalmente o homem é associado ${ }^{67}$. Assim, em um texto que embora rigoroso é de elegante e agradável leitura, Leroi-Gourhan parte dos primeiros vertebrados até o humano a fim de demonstrar como o processo de liberação, relacionado a mudanças esqueléticas, de nutrição e de meio, é constituinte da própria deriva evolucionária. Com a paleontologia de Leroi-Gourhan, Derrida pode estender o conceito de escritura, fazendo-o compreender o fenômeno da técnica, para, respaldado na afirmação do primeiro, permitir a ultrapassagem do humano pelo fenômeno. Afirma Leroi-Gourhan antes de Derrida: "antes da escrita, todo o conhecimento verdadeiro da linguagem é irrealizável"68. E segue:

... a partir de uma fórmula idêntica à dos primatas, o homem fabrica utensílios concretos e símbolos, uns e outros resultantes do mesmo processo ou, melhor, necessitando no cérebro do mesmo equipamento fundamental. Tudo isto leva a considerar não só que a linguagem é tão característica do homem quanto o utensílio, mas ainda que se trata da expressão da mesma propriedade humana, exatamente como os trinta diferentes sinais vocais do chimpanzé são o exato correspondente mental das varas encaixadas para chegar a uma banana suspensa, isto é, nos chimpanzés a linguagem é tão pouco linguagem quanto as varas encaixadas são uma técnica propriamente dita ${ }^{69}$.

Mas para Leroi-Gourhan, "os preensores possuem todos, mesmo os que estão longe dos humanos, as virtualidades fundamentais da

\footnotetext{
65 "Do ponto de vista do 'sucesso biológico uma e outra via conduziram a fins igualmente brilhantes. As medusas sobreviveram sem variar desde há várias centenas de milhões de anos, enquanto os animais móveis, com os vertebrados, forneceram as mudanças necessárias para chegarem à inteligência. Os vencedores dessa corrida interminável, a medusa e o homem, marcam os dois limites extremos da adaptação; entre eles situam-se os dois milhões de espécies que formam o leque da geologia terrestre" (LEROI-GOURHAN. O Gesto e a Palavra, v.I - Técnica e Linguagem, p. 35).

${ }^{66}$ LEROI-GOURHAN. O Gesto e a Palavra, v. I - Técnica e Linguagem, p. 92.

${ }^{67}$ LEROI-GOURHAN. O Gesto e a Palavra, v. I - Técnica e Linguagem, p. 31-32.

${ }^{68}$ LEROI-GOURHAN. O Gesto e a Palavra, v. I - Técnica e Linguagem, p. 115.

${ }^{69}$ LEROI-GOURHAN. O Gesto e a Palavra, v. I - Técnica e Linguagem, p. 116.
} 
técnica"70, se tratando de uma "evolução sincrônica" da utensilagem e dos esqueleto ${ }^{71}$. Além disso, da mesma forma que hoje em biologia falase de "mutualismo", Leroi-Gourhan já registrava como o "acoplamento" entre humanos e cães, por exemplo, foi fundamental para a função de pastoreio, daí a agricultura e dela à "alta cultura"72. Tudo isso contesta o mito dualista, uma das bases da mitologia logocêntrica, da separação entre corpo e espírito ${ }^{73}$. "Em vez de recorrer aos conceitos que servem habitualmente para distinguir o homem dos outros viventes (instinto e inteligência, ausência ou presença da fala, da sociedade, da economia, etc., etc.), apela-se aqui à noção de programa"74. O conceito aparece de modo insistente na obra de Leroi-Gourhan, consistindo em uma espécie de padrão de respostas que o sistema nervoso dirige às solicitações internas e externa ${ }^{75}$. O contraste entre humano e animal, por isso, não se dá em termos de instinto e inteligência, mas como duas formas distintas de programação com diferenças de memorização ${ }^{76}$. Segundo Derrida, deve-se "entendê-la, certamente, no sentido da cibernética, mas esta mesma só é inteligível a partir de uma história das possibilidades do rastro como unidade de um duplo movimento de proteção e retenção"77. Os programas não são, portanto, formas de determinismo diretos inscritas em idealidades suprassensíveis, mas estruturas funcionais plásticas que operam segundo ritmos sociais que "criam" espaço e tempo ${ }^{78}$, possibilitando a acumulação memorizadora e por isso a dilatação do espaço de liberação.

No seus pontos mais especulativos, Leroi-Gourhan chega a falar de uma possível "liberação do cérebro" e mesmo "do indivíduo" a partir da radical exteriorização da memória"9. Toda tese forte e específica de "Da Gramatologia", baseada na convergência entre o linearismo definido a partir de pressões técnico-econômicas que deram origem à metafísica da presença e ao fonologocentrismo são diretamente legíveis no trabalho

$\overline{70}$ LEROI-GOURHAN. O Gesto e a Palavra, v. I - Técnica e Linguagem, p. 84. Ainda: idem, p. 110, 219 (nota 7); idem, O Gesto e a Palavra, v. II - Memória e Ritmos. Porto: Edições 70, 1983, p. 11.

71 "Creio efetivamente que, a estes níveis, ligando o progresso técnico com o biológico, mais não faço que verificar um fenômeno comparável à ligação, a partir do homo sapiens, do mesmo progresso técnico com a organização do grupo social" (LEROI-GOURHAN, O Gesto e a Palavra, v. II - Memória e Ritmos, p. 134).

${ }^{72}$ LEROI-GOURHAN. O Gesto e a Palavra, v. I - Técnica e Linguagem, p. 144.

${ }^{73}$ LEROI-GOURHAN. O Gesto e a Palavra, v. I - Técnica e Linguagem, p. 108-110, 118-119, 148-150.

${ }^{74}$ DERRIDA, Jacques. Gramatologia, p. 104.

${ }^{75}$ LEROI-GOURHAN, O Gesto e a Palavra, v. II - Memória e Ritmos, p. 14.

${ }^{76}$ LEROI-GOURHAN, O Gesto e a Palavra, v. II - Memória e Ritmos, p. 15-17 e 20-21.

${ }^{77}$ DERRIDA, Jacques. Gramatologia, p. 104.

${ }^{78}$ LEROI-GOURHAN, O Gesto e a Palavra, v. II - Memória e Ritmos, p. 117-118.

${ }^{79}$ LEROI-GOURHAN, O Gesto e a Palavra, v. II - Memória e Ritmos, p. 51. 
de Leroi-Gourhan ${ }^{80}$ (tendo sido posteriormente repetidas, no âmbito da antropologia filosófica, por Stiegler ${ }^{81}$ ). O paleontólogo já colocava, entre outros pontos, o caráter de intrincação entre a linguagem fonética e o linearismo, a existência de modelos multidimensionais em outras culturas e como, em algumas ciências, o linearismo constituía um entrave a superar, dada sua unidimensionalidade ${ }^{82}$. "O modelo enigmático da linha", diz Derrida, "é aquilo mesmo que a filosofia não podia ver enquanto tinha os olhos abertos sobre o dentro de sua própria história. Esta noite se desfaz um pouco no momento em que a linearidade - que não é uma perda ou uma ausência, mas o recalcamento do pensamento simbólico pluridimensional - afrouxa sua opressão porque começa a esterilizar a economia técnica e científica que, durante muito tempo, ela favoreceu". E segue: "o fim da escritura linear é o fim do livro"83.

Todo problema da memorização, que Derrida cruzará também com Freud e Husserl radicalizando a ideia de "prótese de dentro", encontra respaldo nesses trabalho ${ }^{84}$. É esse ponto que Bernard Stiegler, inspirado na Gramatologia, irá levar adiante, trazendo Leroi-Gourhan entre seus fundamentos para pensar uma antropologia filosófica diretamente conectada com a técnica, na qual o próprio mito da queda é substituído pela economia da diferença na qual a tecnicidade questiona o próprio valor da origem, ainda hoje extremamente influente por exemplo nas teorias da "segunda natureza" humana ou mesmo no naturalismo. $O$ processo é então nomeado de "epifilogênese" 85 .

\section{Conclusão: a materialidade da escritura}

Sem a retomada integral do período de pesquisa entre 1965 e 1967 por Derrida, torna-se inviável dimensionar simplesmente o papel da escritura. Cai-se, na realidade e apesar das aparências, em um conceito puramente transcendental no qual a remissão infinita passa a apagar a opção pela metonímia escritural contra o privilégio fonético ou, inversamente, no simples sentido empírico. Se, de fato, "o nome, em singular o nome dito próprio, está sempre preso numa cadeia ou num sistema de diferenças"

\footnotetext{
${ }^{80}$ LEROI-GOURHAN. O Gesto e a Palavra, v. I - Técnica e Linguagem, p. 187-215.

${ }^{81}$ STIEGLER, Bernard. Technics and Time, 2: Disorientation. Trad. Stephen Barker. Stanford: Stanford University Press, 2009, passim.

${ }^{82}$ LEROI-GOURHAN. O Gesto e a Palavra, v. I - Técnica e Linguagem, p. 196-197.

${ }^{83}$ DERRIDA, Jacques. Gramatologia, p. 107-108.

${ }^{84}$ LEROI-GOURHAN, O Gesto e a Palavra, v. II - Memória e Ritmos, p. 22-31 e 55ss.

${ }^{85}$ STIEGLER, Bernard. Technics and time, 1: the fault of Epimetheus. Trad. Richard Beardworth and George Collins. Stanford: Stanford University Press, 1998, p. 116-133. Para uma ideia geral do pensamento de Stiegler, ver PINTO NETO, Moysés. "Bernard Stiegler: pensador da tecnologia e do humano". Dois Pontos (UFPR), v. 12. 2015.
} 
e o "próprio do nome não escapa ao espaçamento" 86 , é também verdade que isso não subsume o sentido material que a expressão gráfica - a inscrição - carrega em relação às idealidades filosóficas. Diz ele:

A 'ciência' semiológica ou, mais estritamente, linguística, não pode conservar a diferença entre significante e significado - a própria ideia de signo - sem a diferença entre o sensível e o inteligível, é certo, mas também sem conservar ao mesmo tempo, mais profunda e mais implicitamente, a referência a um significado que possa 'ocorrer', na sua inteligibilidade, antes de sua 'queda', antes de toda expulsão para a exterioridade do 'este mundo sensível'. Enquanto face da inteligibilidade pura, remete a um logos absoluto, ao que está imediatamente unido. Este logos absoluto era, na teologia medieval, uma subjetividade criadora infinita: a face inteligível do signo permanece voltada para o lado do verbo e da face de Deus ${ }^{87}$.

Apesar disso, não será simplesmente pela eliminação do significado que a questão se resolverá, pois a "exterioridade do significante é a exterioridade da escritura em geral" ${ }^{88}$. O filósofo descarta a simples inversão que tornaria o significante primeiro.

O 'primado'”, diz, "ou a 'prioridade' do significante seria uma expressão insustentável e absurda, se formulada ilogicamente na mesma lógica que ela quer, legitimamente sem dúvida, destruir. Nunca o significante precederá de direito o significado, sem o que não seria mais significante e o significante 'significando' não teria mais nenhum significado possível. O pensamento que se anuncia nessa impossível fórmula sem conseguir alojar-se nela, deve portanto enunciar-se de outro modo: e somente poderá fazê-lo, se lançar a suspeição sobre a ideia mesma de 'signo-de', que permanecerá sempre ligada àquilo mesmo que aqui se coloca em questão. Portanto, no limite, destruindo toda a conceitualidade ordenada em torno do conceito de signo (significante e significado, expressão e conteúdo etc. $)^{89}$.

A exterioridade do significante é a exterioridade da escritura que se afasta da plena presença. Do signo passa-se então ao grafema. Essa exteriorização, como vimos a partir de Leroi-Gourhan (e certamente seria possível associar a Emmanuel Levinas) é a materialidade que desfaz o privilégio da idealidade enquanto elemento da ontoteologia que, na busca da parousia absoluta, busca apagar seus próprios rastros. A grafemática é, por isso, um materialismo do rastro. O pensamento da

\footnotetext{
${ }^{86}$ DERRIDA, Jacques. Gramatologia, p. 113.

${ }^{87}$ DERRIDA, Jacques. Gramatologia, p. 16.

${ }^{88}$ DERRIDA, Jacques. Gramatologia, p. 17.

${ }^{89}$ DERRIDA, Jacques. Gramatologia, p. 23, nota 9.
} 
escritura equaciona, simultaneamente, a incapacidade de o materialismo ir além do substancialismo atomista, desprezando o aspecto formal que Husserl soube explorar à exaustão, e a metafísica das formas eternas que abastece o hilemorfismo platonista da tradição. A escritura permita cruzar esses dois campos, permitindo-se equacionar, de um só golpe, empírico e transcendental, formal e material, contingência e necessidade.

A tentativa de conter a escritura no interior da episteme - que a subordina, como mais tarde será tratado por Derrida em outros escritos seminais como A Farmácia de Platão, aos valores da soberania (Rei), da clareza (Sol), ao falocentrismo (Pai) ou à moral (Bem) - é o que impossibilita o surgimento puro e simples de uma gramatologia ${ }^{90}$. Entender, contudo, suas raízes tanto científicas quanto materiais nos coloca diante de outra forma de relação com o pensamento derridiano, mais centrada na realidade sulcada pela inscrição que pelo jogo intertextual de significantes. O contraste com a linguagem, cuja inflação é um destino histórico que certo pensamento tinha que consumar, está na sua inscrição material, sempre tomado como afastamento da origem pura, ideal, que a tornaria necessariamente inferior, assessória, até imoral. Mas ao mesmo tempo simplesmente contê-la no seu uso habitual, sem compreendê-la como metonímia da inscrição no real, torna o pensamento derridiano passível das interpretações que mais o neutralizam que o potencializam, limitando o sentido do texto à dimensão menos produtiva e transformadora. No fim do texto de Da Gramatologia, então, a possibilidade de um entrecruzamento ao modo semiológico se coloca diante de uma tarefa mais difícil: a de formular um pensamento que não pesa nada, mas enceta-se na episteme, arrobando seus próprios limites. A escritura, assim, irá gradualmente perdendo ênfase para a desconstrução. Começa então outra história.

\section{Referências}

BARING, Edward. The Young Derrida and French Philosophy, 1945-1968. New York: Cambridge University Press, 2011.

CENTRE INTERNATIONAL DE SYNTHÈSE. L'écriture et la psychologie des peuples. XXII Semaine de Synthèse. Paris: Armand Colin, 1963.

DAVID, Madeleine V. Le débat sur les écritures at l'hiéroglyphe aux XVIIe et XVIIIe siècles - et la application de la notion de déchiffrement aux écritures mortes. Paris: S.E.V.E.N, 1965.

DELEUZE, Gilles; GUATTARI, Félix. Mil Platôs, v. 1. Trad. Aurélio Guerra e Costa Pinto. Rio de Janeiro: Editora 34, 1995.

${ }^{90}$ Sobre o tema, ver PINTO NETO, Moysés. "Nós fora de nós: Derrida, Stiegler e os sistemas de cognição estendida". Sapere Aude, v. 4, n. 7. 2012, passim. 
M. Pinto Neto - O conceito de escritura em Derrida e a gramatologia ...

DERRIDA, Jacques. "Introduction". In: HUSSERL, E. L'Origine de la géométrie. Paris: PUF, 1962.

. A Escritura e a Diferença. Trad. Maria B. M. Nizza da Silva et al. 4. ed. São Paulo: Perspectiva, 2010.

. Gramatologia. Trad. Miriam Chnaiderman e Renato Janine Ribeiro. São Paulo: Perspectiva, 2004.

. De la Grammatologie. Paris: éditions de Minuit, 1967.

. A Farmácia de Platão. Trad. Rogério Costa. São Paulo: Iluminuras, 2005.

. Posições. Trad. Tomaz Tadeu da Silva. Belo Horizonte: Autêntica, 2001.

DERRIDA, Jacques; STIEGLER, Bernard. Echographies of Television. Trad. Jennifer Bajorek. Polity, 2002.

DUQUE-ESTRADA, Paulo César. "Derrida e a escritura". In: Às margens: a propósito de Derrida. Rio de Janeiro: PUC-Rio/Loyola, 2002.

HÄGGLUND, Martin. Radical Atheism: Derrida and the time of life. Stanford: Stanford University Press, 2008.

JOHNSON, Christopher. System and Writing in the philosophy of Jacques Derrida. Cambridge: Cambridge University Press, 1993.

. “The cybernetic imaginary". In: Reading Derrida's Of Grammatology. Ed. Sean Gaston e Ian Maclachlan. London: Continuum, 2011.

. Derrida: a cena da escritura. São Paulo: Editora UNESP, 2001.

KIRBY, Vicki. “Tracing life: 'la vie la mort'”. The new continental review, 9, 1 (2009), p. 107-126.

. "Original science: nature deconstructing itself". Derrida Today, 3, 2 (2010).

LEROI-GOURHAN, Andre. O gesto e a palavra, v. I - Técnica e linguagem. Porto: Edições 70, 1983.

. O gesto e a palavra, v. II - Memória e ritmos. Porto: Edições 70, 1983.

LOBO, Rafael Haddock. Derrida e o labirinto de inscrições. Porto Alegre: Zouk, 2008.

MALABOU, Catherine. La plasticité au soir de l'écriture: dialetique, destruction, déconstruction. Paris: Éditions Léo Scheer, 2005.

PEETERS, Benoît. Derrida. Trad. André Telles. Rio de Janeiro: Civilização Brasileira, 2013.

PINTO NETO, Moysés. A escritura da natureza: Derrida e o materialismo experimental. Tese de Doutorado defendida no PPG Filosofia da PUCRS. Porto Alegre, 2013.

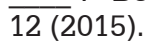

. "Bernard Stiegler: pensador da tecnologia e do humano". Dois Pontos, UFPR, . "Nós fora de nós: Derrida, Stiegler e os sistemas de cognição estendida". Sapere Aude, 4, 7 (2012).

RODRIGUES, Carla. "Kafka, Benjamin e Derrida: diante da lei". Terceira Margem, 28 (jul./dez. 2013).

STADEN, Henri. "Writing: empirical, transcendental, ultratranscendental". CR: The New Centennial Review, 9, 1 (Spring 2009). 
STIEGLER, Bernard. Technics and time, v. 1 - The fault of Epimetheus. Trad. Richard Beardworth and George Collins. Stanford: Stanford University Press, 1998.

Technics and Time, v. 2 - Disorientation. Trad. Stephen Barker. Stanford: Stanford University Press, 2009.

WOLFREYS, Julian. Compreender Derrida. Rio de Janeiro: Vozes, 2007.

\section{Endereço postal:}

Av. Farroupilha, 8001 - Bairro São José

Canoas, RS, Brasil

Data de recebimento: 07-06-2017

Data de aceite: 25-08-2017 